\title{
Study on Electric Vehicles in India Opportunities and Challenges
}

\author{
Mohamed $\mathbf{M}^{1 *}$, G Tamil Arasan ${ }^{1}$ and G Sivakumar ${ }^{2}$ \\ ${ }^{1}$ Department of Electrical and Electronics Engineering Panimalar Engineering College Chennai, India \\ ${ }^{2}$ Department of Chemistry Panimalar Engineering College Chennai, India
}

Received: January 27, 2018; Accepted: Feburary 12, 2018; Published: February 16, 2018

*Corresponding author: Mohamed M, Department of Electrical and Electronics Engineering Panimalar Engineering College Chennai, India, E-mail: mmohamed.official@gmail.com

\begin{abstract}
Over the years, the exploitation and pollution of natural resources have created the need for renewable and environment-friendly products. One of these products is Electric Vehicles. Electric Vehicles are the replacement for petroleum-based vehicles. They are one of the emerging technologies as well as eco-friendly and viable. The replacement of internal combustion engines with electric engines will reduce pollution to a great extent and be profitable to consumers. Many countries around the globe have implemented this technology and are contributing towards amelioration of the environment. We are going to see the opportunities and challenged faced in India over implementing electric vehicles.
\end{abstract}

Keywords: Pollution; Electric Vehicle; Eco-Friendly; Lithium Battery;

\section{Introduction}

The use of non-renewable and polluting sources for the production of energy has taken environmental pollution to a whole new level. The increasing global warming has an impending need on us to stop the use of non-renewable resources and reduce carbon emissions. Since the industrial age, the atmospheric carbon content is rising. Carbon emissions from vehicles amount for a typical passenger vehicle is 4.7 metric tons per year. The largest human source of carbon emission is from combustion of fossil fuels. The development of electrical engine in vehicles has created a replacement for the internal combustion engines paving way for the Electric Vehicles (EV). EVs have been adopted by many countries since it development creating a positive impact on the environment. We are now going to see the opportunities and challenges impending over implementing electric vehicles in India.

\section{Types of Electric Vehicles}

\section{A. Ground Vehicles}

- Battery Electric Vehicles (BEVs)

- Hybrid Electric Vehicles (HEVs)
- Rail borne Electric Vehicles

- Space Rover VehiclesEstimation of MSW Generated Within the City

\section{B. Airborne Vehicles}

- Manned \& Unmanned Electric Aerial Vehicles

\section{Seaborne Vehicles}

- Electric Boats

\section{Battery Electric Vehicles (BEVs)}

Battery Electric Vehicles are complete electric vehicles that are powered by only electricity and do not include a petrol/diesel engine, fuel storage or exhaust pipe. They use electric motors and motor controllers for propulsion. They do not have an internal combustion engine. They charge the battery through external charging outlet and hence also known as "Plug-in Electric Vehicles (PEVs)". There are various types of BEVs such as electric cars, buses, bikes, scooters, trucks and trains. They even include fewer parts than those used for those vehicles based on internal combustion engines. They even produce fewer noises compared to their counterparts.

\section{Hybrid Electric Vehicles (HEVs)}

Hybrid Electric Vehicles are not pure electric vehicles since they use a combination of internal combustion engine and electric propulsion systems. These mainly include cars, buses and trucks. The latest models use technologies focusing on improving efficiencies such as regenerative brakes, which convert kinetic energy of vehicle into electric energy to charge the battery and other systems such as start-stop system, which switches off the engine at idle and restarts when needed to reduce idle emissions and motor-generator. A hybrid electric produces much less emission than those produced by pure gasoline based hybrids improving fuel economy functioning at maximum efficiency. There are also Plug-in Hybrid Vehicles (PHEVs). They even produce fewer noises than pure hybrid vehicles. 


\section{Advantages of using Electric Vehicles}

\section{A.Cheaper to operate}

EVs are cheaper to operate since they have high efficiencies and fuel economies thereby reduce cost for the owner. The electricity to charge an EV is about one third as much per kilometer to purchase fuel for vehicle [1].

\section{B. Cheaper to maintain}

BEVs have less moving parts than those had by conventional combustion engine vehicles. There is less servicing and no expensive systems such as fuel injection and exhaust systems, which are not needed in an EV. PHEVs have petrol engine and need servicing hence costing more than BEVs but they also have an electric propulsion system, which requires less moving parts leading to less depletion of petrol engine parts [2].

\section{Environment Friendly}

EVs are less polluting, as they have zero exhaust emissions [3]. If you opt to use renewable energy to charge your EV, you can reduce green house gas emissions even more. Some EVs are made of eco-friendly materials such as the Ford Focus Electric, which is made of recycled and bio based materials and the Nissan Leaf which is partly made of recycled plastic bottles, old car parts and second hand appliances [4].

\section{Health Benefits}

The reduced harmful emissions will lead to better air quality, which is good for our health. EVs are also produce much less noise compared to petrol/diesel-based vehicles [31]

\section{E. Safer}

EVs have a low center of gravity thereby making them less likely to capsize. They also have low risk of fires and explosions. Their body construction gives them more durability hence making them safer during collisions [5].

\section{Electric Vehicle Timeline}

- 1832 - Robert Anderson develops First Crude Electric Vehicle [32].

- 1890 - William Morrison develops first successful electric vehicle in the USA [33].

- 1899 - Electric Cars gain popularity

- 1900 - Electric Cars are the trend

- 1901 - The World First Hybrid Electric Car, the "Lohner Porsche Mixed" is created by Ferdinand Porsche[34]

- 1908 - The Ford Model T is introduced by Henry Ford [35].

- 1912 - The Electric Starter is introduced [36].

- 1920 - 1935 - Decline in electric vehicles due to use of crude Texas Oil as fuel

- 1960s - Interest in electric vehicles regain as Fuel prices soar
- 1971 - First Manned Electric Vehicle for the moon, NASA's Lunar Rover is developed [37].

- 1973 - Many Automakers explore alternative options to fuel

- 1974 - Sebring Vanguard introduces the 'Citi Car' [38].

- 1979 - Interest in Electric Cars fade due to drawbacks

- 1990 - Clean Air Amendment Act is passed [39].

- 1992 - Energy Policy Act is passed [40].

- 1996 - General Motors launch EV1 [41].

- 1997 - Toyota produces the first mass produced hybrid, the 'Prius' [42].

- 2006 - TESLA announces production of luxury electric cars

- 2008 - TESLA produces its first electric vehicle, the Roadster with range of 244 miles per charge[43].

- 2009 - US Energy Department invests in nation-wide charging infrastructure [44].

- 2010 - General Motors introduce first Plug In Hybrid, the Chevy Volt [45].

- Nissan introduces LEAF, an all electric, zero emission cars [46].

- 2012 - TESLA introduces Model S with battery range of 270 miles per charge [47].

- 2013 - Cost of Electric Vehicle Batteries drop by 50\% [48].

- 2014 - TESLA announces plan to build 'Gigafactory' and double worlds 2014 battery production figures [49].

- 2016 - BMW Group, Daimler AG, Volkswagen Group with Audi and Porsche along with Ford Motor Company (European Division) agree to build ultra fast charging sites across Europe by 2020 [50].

- 2017 - Toyota announces sales of 10 million hybrids since production of 'Prius'.

- 2019 - Expected date by which Swedish Automaker Volvo announces to produce only electric and hybrid cars [25].

- 2020 - China's expectation of $10 \%$ of auto imports and production will be only electric vehicles[51].

- 2025 - Expected date by which Norway and Netherlands plan to ban sales of petrol and diesel cars[52].

- 2030 - Expected date by which India plans to promote an all-electric car fleet [7]. Also, China expects to limit its carbon emissions, hence affecting sales of petroleum-based cars [53].

- 2040 - Expected date by which Britain and France announce plans to ban sales of all new petroleum based vehicles [54]. 


\section{India's Progress with Implementation of Electric Vehicles}

The Government of India has embarked on a mission to create revolution in renewable energy in the country by planning a movement involving transformation to Electric Vehicles by 2030[7]. It is expected to cut its oil purchases by some $\$ 60$ billion, reducing emissions by $37 \%$ and curb demand for road infrastructure within the next 12 years[9]. India currently has around 1.3 billion people with around 21 million vehicles sold annually [7].

\section{Opportunities}

\section{A. Government Initiatives}

- In 2015, the Government introduced a scheme called the Faster Adoption and Manufacturing of hybrid and Electric vehicles (FAME) in order to promote electric vehicles [10].

- In 2015, the National Electric Mobility Mission Plan was drafted to achieve fuel security by expecting to achieve sales of electric and hybrid cars to reach six to seven million by 2020 [14].

- State run firm Energy Efficiency Services Limited (EESL) has appointed the nodal agency to procure around 10,000 electric cars to replace existing government vehicles [11].

- The Karnataka State Government has approved a policy to promote research and development in electric mobility making it mandatory to have charging points and pods in all major cities of the state [12].

- The Maharashtra State Government waived off some taxes for Electric Vehicles ever since it became India's First State to have an Electric Mass Mobility System.

- India is obligated to bring down its share of global emissions by 2030 as a signatory to the Paris Climate Agreement [8].

- The Government plans to setup lithium-ion battery making facility under supervision of Bharat Heavy Electricals Limited (BHEL) [17].

- The Goods and Services Tax (GST) Council has set a tax rate of $12 \%$ compared to $28 \%$ set for petroleum based vehicles [26].

\section{B. Battery}

- Presently, around 22,000 EV units are being sold, among which around 2000 of them are 4 wheeler vehicles [15].

- Battery prices have declined from $\$ 600$ in 2012 to $\$ 250$ in 2017 and are expected to fall to $\$ 100$ by 2024 making it cheaper than capital cost of petrol vehicles [16].

- The storage capability of EV batteries can help with grid balancing

\section{Industrial}

- Taxi aggregator OLA has launched OLA Electric project aiming to build an electric mobility ecosystem including charging infrastructure and vehicle fleets such as electric cabs, e-rickshaws and much more [13].
- Suzuki has announced its plan to setup a $\$ 600$ million lithium ion battery facility [18].

- Mahindra has announced investment of around 60 million rupees to develop its EV division expecting to launch electric variants of its vehicles [23].

- Cummins India, an engine manufacturer is researching on electric mobility solutions.

- Ashok Leyland has announced a partnership with SUN Mobility to develop battery swapping system for electric buses [19].

- JSW Energy has announced its plan to invest \$623 million in electric cars, batteries and charging infrastructure [20].

- Swedish Automaker Volvo has announced that they will phase out the internal combustion engine and manufacture only electric or hybrid vehicles by 2019 [25].

- Companies setting up charging infrastructure have an advantage; provided the lucrative market potential is projected to be about 90 billion units (BU) and India generated 1,107 BU in 2015 - 2016 [24].

\section{Environmental}

- Most metropolitan cities are experiencing high Air Pollution rates, with vehicular emissions being one of the major pollutants.

- India's capital city Delhi has started experiencing smog through the city due to large amounts of air pollution [27].

- The use of recycled and old car parts in EVs makes it even more eco friendly

- Increase in awareness of Climate Change promotes the production and sales of EVs.

- Rise in Pollution awareness also promotes the production and sales of EVs.

\section{Challenges}

\section{A. Cost of EVs}

- The cost of EVs should be reasonable and the EVs produced should hold proper value for money.

\section{B. Efficiency of EVs in India}

- The EVs in India on an average provide around $120 \mathrm{~km}$ on a full charge in turn making them unsuitable for long drives [21].

- EVs in India lack speed, which may turn off buyers. The top two India made EVs have speed of $85 \mathrm{~km} / \mathrm{hr}$. [22].

\section{Demand for EVs}

- Increase in demand will help in achieving vision 2030.

- Increase in demand of EVs will lead to increase in requirement for energy and raw materials to for the battery. 


\section{Vehicle Quality}

- Good vehicle quality will lure more customers.

- Better quality vehicles ensure trust among customers.

\section{E. Batteries}

- The batteries used by electrics are cars made up of nickel, aluminum, cobalt, graphite and lithium, which are all rare earth materials.

- The availability of these materials is scarce and the amount of these materials available may not be able to produce enough batteries to power the expected amount of electric vehicles to be produced.

- The increasing demand for lithium around the globe given its scarcity on the Earth's surface will make it challenging to meet India's EV requirement.

\section{F. Electricity Generation}

- There must be enough electricity generation capacity to meet the increasing demands for charging infrastructure and local consumer utilization.

- There is presently shortage of electricity in many parts of India and a major part of energy generation of the country is still dependent on fossil fuels [30].

\section{G. Anti - EV Elements}

- Anti - EV activists, supposedly fringe elements hired by oil companies or fossil fuel dealers try to thwart growth of EVs. Amsterdam recently witnessed an Anti - EV vandalism case involving damaging of 2 TESLAs [28].

\section{H. Global Energy Demand}

- Any decrease in demand for oil by India and China will have wide geopolitical ramifications as the two countries together account for half of $1 \%$ growth in global energy demand in 2016 [6].

\section{Land Availability}

- Availability of land to setup charging stations in urban areas where land scarcity is present is a difficult task.

- Moreover, a substation nearby is a requirement for a charging station [29].

\section{Conclusion}

The implementation of EVs in India aims primarily to reduce greenhouse gas emissions and cut oil expenses. The vision 2030 put forth by the Indian Government is an ambitious and difficult task. The Government should make the most out of the opportunities available and find suitable ways to tackle the challenges impending over the implementation of EVs. India's obligation towards many environment friendly agreements has given it a situation where it is prompted to implement vision 2030.

\section{Acknowledgment}

We would like to express our sincere gratitude and appreciation to all those who gave us the possibility to complete this study. We would like to thank our Honorable Secretary and Correspondent Dr. P Chinnadurai and Director Mr. C Sakthikumar. We would like to extend our goodwill to our Head of Department Prof. S Selvi, along with Prof. Stephen Silas, Prof. V Devaraj and Prof. B Vijayakumar and who coordinated us throughout this study. Last but not the least we thank our parents, staff members and all our supporters for their prayers and wishes.

\section{References}

1. Benefits of electric vehicles as outlined by the Australian Electric Vehicles Association.

2. What are the financial benefits of owning an electric vehicle.

3. Generally, there are still emissions associated with the electricity used to charge an EV if it's from the grid.

4. Environmental Benefits of Electric Vehicles.

5. What are the driving benefits of an electric vehicle.

6. BP Statistical Review of World Energy.

7. India is about to embark on the most ambitious electric-car transformation in the world.

8. Releuctant India takes moral high ground on Paris climate deal.

9. Electric Vehicles to save $\$ 60$ billion in fuel costs by 2030: Niti Aayog.

10.Fame India Scheme.

11.EESL to procure 10,000 electric vehicles to replace government's fleet.

12.Karnataka wants to become the electric vehicle capital of India.

13.Nagpur gets India's first fleet of electric vehicles.

14.National Electric Mobility Mission Plan.

15.India's electric vehicle sales grow $37.5 \%$ to 22,000 units.

16. What India needs to do to give electric vehicles a push.

17.Govt eyes made-in-India lithum ion batteries to lower cost of electric vehicles.

18.Suzuki Motors starts work on lithium ion battery.

19.Coming soon to India: Electric buses that can swap batteries at petrol pump-like facilities.

20.India's JSW Energy to invest up to $\$ 623$ million in electric cars.

21.Mahindra Reva e2o to go $120 \mathrm{kms}$ per charge, power steering added!

22.Top 5 Hybrid/Electric Cars in India.

23.Mahindra Scorpio and XUV500 to get electric versions soon, M\&M to invest Rs. 300-400 crore on EVs.

24.India's electric vehicle drive.

25.Volvo Electric Future.

26.Govt sets low GST rate for electric vehicles to boost sales, but its not enough.

27.How Delhi became the most polluted city on Earth.

28.Anti EV Activists set two TESLAs on fire. 
29.BEAMA Guide to Electric Vehicle Infrastructure.

30.Power Problems Threaten Growth in India.

31.Reducing Pollution with Electric Vehicles.

32.History of the Automobile.

33.The Morrison Electric Automobile \& The William Morrison Co.

34.Lohner -Porsche Mixed Hybrid.

35.Model T.

36.Patent for Engine Starting Device.

37.Apollo 15 Lunar Module and Rover.

38.1974 Vanguard Sebring CitiCar.

39.1990 Clean Air Act Amendment Summary.

40.Summary of Energy Policy Act.

41.Quiroga, Tony. "Driving the Future". Car and Driver. Hachette Filipacchi Media. 2009; US.

42.The birth of the Prius

43.Roadster Efficiency and Range.
44.President Obama Announces \$2.4 Billion in Grants to Accelerate the Manufacturing and Deployment of the Next Generation of U.S. Batteries and Electric Vehicles.

45.Chevy Volt: Motor Trend Car of the Year.

46.Nissan Leaf electric prototype review. 2010;

47.A Brief History Of Tesla Cars in One Simple Infographic.

48.EV Battery Prices: Looking back a few years, \& forward yet again.

49.Nevada a winner in Tesla's Battery Contest.

50.BMW Group, Daimler AG, Ford Motor Company and the Volkswagen Group with Audi and Porsche form Joint Venture: IONITY-PanEuropean High-Power Charging Network Enables E-Mobility for Long Distance Travel.

51.China extends its electric car rebate to 2020 in attempt to secure EV adoption lead.

52.More than half of Norway car sales now electric or hybrid.

53.China vowed to peak carbon emissions by 2030 . It could be way ahead of schedule.

54.Britain to ban sale of all diesel and petrol cars and vans from 2040. 